chloric acid as the agent of inversion, since the process requires no attention, and the error introduced by the hydrolysis of dextrin is less even when the most favorable method of inversion is used; viz., heating for ten minutes, regulating the temperature so as to reach $68^{\circ}$ at the expiration of that time.

OHIO STATE Uiviversity,

COLUMBUS, OHIO.

\title{
METHOD OF DETERMINING CHROMIUM IN CHROME ORE.
}

BY Fidund Clark.

Received February 8, I895.

DROF. STORER and others have suggested the use of nitric acid and potassium chlorate as agents for the oxidation of chromic compounds to chromic acid. Using this suggestion as a basis for the determination of chromium in chrome iron ore, I have experimented with a method which has proved both practicable and accurate.

For complete analysis a half gram sample of the finely ground ore is weighed into a platinum crucible with a capacity of not less than fifty $\mathrm{cc}$. The ore is covered with twenty-five grams of potassium bisulphate and fusion is commenced over a Bunsen burner with very low flame which is protected from air currents by a sheet iron chimriey.

To insure complete fusion, and to guard against any loss, the operator must manipulate carefully and watch the operation from beginning to end. At first, the flame should be so low as to fuse the bisulphate very slowly.

After the mass is in a liquid condition, and there is no longer any danger of loss from spattering, the crucible is grasped with a pair of crucible tongs and the contents are run up around the sides, in order to seize hold of any particles of ore which may have become stranded there.

At this stage of the process, the flame may be increased a little so as to cause a tolerable redness of the bottom of the crucible.

At intervals of ten minutes the crucible must be manipulated by the operator as before described. Forty minutes will suffice for complete decomposition of the ore. Pour the contents into a perfectly clean and dry, four to five-inch platinum evaporating 
dish, making as thin a layer of the mass as possible. Place the crucible and cover in a twelve-ounce beaker and reserve for the solution.

Cool the contents of the dish quickly by means of a shallow ressel of cold water, which should be immediately at hand. Corer the dish with a suitable watch-glass to prevent loss of particles by the sudden contraction of the cooling mass. When cool, rinse off the watch-glass and add thirty-five cc. of hydrochloric acid (r.2O sp.gr.) and twenty-five cc. of water.

Boil quietly over the flame, keeping the watch-glass on, until the solution is complete, usually requiring abont fifteen minutes. Transfer the solution, with care, to the beaker containing the crucible and warm on the steam-bath until the crucible and cover can be washed free from the bisulphate fusion. The solution now occupies about roo cc.

Iet contents practically settle, then decant the clear supernatant fluid into another twelve-ounce beaker and add fifteen cc. more of hyolochloric acid to the residue. Heat on the steanbath until nothing but silica remains undissolved. Unite solutions and filter, reserving the filtrate and igniting the filter. Weigh as silica.

The filtrate, which should be easily contained in a twelveounce beaker, is now rendered slightly: alkaline with ammonia.

The dirty, reddish green precipitate consists of the hydroxides of chrominn aluminum, and iron. 'These are warmed on the steam-bath until the smell of ammonia is faintly perceptible. Filter on a fifteen $\mathrm{cm}$. filter without washing and dissolve the collected hydroxides into the original beaker, with dilute hydrochloric acid. Reprecipitate with ammonia and collect on the same filter as before, washing carefully three times with hot water, combine the two filtrates, and in the united solution determine lime and magnesia by any good method.

Transfer the filter containing the precipitated hydroxicles to a four and one-half inch porcelain evaporating dish and cover with a five-inch watch-glass. Add fifty cc. of nitric acid ( 1.42 sp. gr.) and heat gently over a Bunsen flame. From time to time carefully add potassium chlorate with a small glass or porcelain spatula. The addition of this reagent is attended with small 
explosions, which should be reduced in violence, as much as possible, by adding small quantities and not too frequently. Great care should be taken here to avoid loss from spattering.

The gradual oxidation may be noticed by the changing of the dirty green color of the emulsion to a clear orange-red solution. The organic matter of the filter-paper has been completely oxidized along with the chromic hydroxide. The complete oxidation is easily detected, but a snall excess of potassium chlorate is added to insure it. The chromium now exists as chromic acid.

Transfer the solution to a twelve-ounce beaker, making up to about $\mathrm{I} 50 \mathrm{cc}$. with water, and precipitate the iron and alumina with ammonia. Filter into a sixteen-ounce beaker without washing. Dissolve the precipitate on the filter with warm, dilute nitric acid and wash thoroughly, allowing the solution to run into the beaker in which the precipitation was made. Reprecipitate with ammonia and throw the precipitate on the same filter, allowing the filtrate to be caught in the same beaker as was the first filtrate. Separate, and determine, the iron and alumina by any good method.

The ammoniacal filtrate contains the chromium as ammonium chromate. Acidify with hydrochloric acid and add a sufficient quantity of strong sulphurous acid water to completely recluce the chromium. The clear, bright green color imparted to the solution is an indication of the complete reduction.

The excess of sulphurous acid must be driven off. This may be done by boiling, but it may be accomplished in a highly satisfactory manner by leaving the open beaker remain on a steam-bath over night.

Upon the complete removal of the sulphurous acid, the solution is rendered just alkaline with amonia, with a final addition of three or four drops in excess. Stir well with a glass rod and heat over a lamp until the smell of ammonia is only faintly perceptible. We have, now, a precipitate of chromium hydroxide ready for filtration. Filter on a $2.5 \mathrm{~cm}$, filter and allow it to drain without washing out the beaker or washing the precipitate. After the precipitate has drained, wash it carefully back into the beaker by inverting the funnel and using warm water. Add more warm water and stir to insure complete solution of all alkaline salts. 
Throw the precipitate back upon the same filter and wash three times with hot water. Drain, dry and ignite in a platinum crucible and weigh as chrominm sesquioxide.

Another method of determining the chromium in the yellow solution of ammonium chromate, and one which many chenists may consider the more expedient, is as follows :

Moderately acidify the ammonium chromate solution with acetic acid and warm. Add an excess of a clear solution of plumbic acetate and allow the precipitate of plumbic cliromate to settle in a warm place for several hours: then collect on a weighed filter (previously dried at $100^{\circ} \mathrm{C}$.) and wash with cold water.

Dry at a temperature of $100^{\circ}$ to $110^{\circ} \mathrm{C}$, and weigh. The increase of weight is the weight of the plumbic chromate, from which the percentage of chromic oxide may be calculated.

The choice given to either of these methods for the final precipitation of chromium is purely arbitrary.

In a future article the method employed in the estimation of chromium in chrome steel and ferro chrome will be dealt with.

\section{NEW BOOKS.}

PROCEFDINGS OF THE ELFVENTH ANNUA CONVENTION OF THE AssociaTION OF OfFicial, Agrictiturat, ChFMists, BUlletin No. 43, U. S.

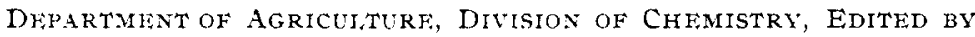
Dr. IH. W. WILEY, pp. 403. Washington: Government Printing Office. 1894.

This bulletin issued annually through the courtesy of the $U$. S. Department of Agriculture, contains, as usual, the results obtained by the various reporters appointed by the Association, a general discussion of their reports, and a complete summary of the methods of agricultural chemical analysis which are now almost universally used in this country and which have official recognition.

Some sixty chemists participated in the meeting, and the very full discussions denote a lively interest in the work. For the first time a committee was appointed to consider the changes of method recommended by the various reporters and to approve the same before submitting them for action. Most of the changes recommended were approved by the committee. It is, however, gratifying to note that these changes were, as a rule, unimpor- 